\title{
Luau Astronômico: a formação inicial de professores como divulgadores científicos em ambientes não for- mais $^{+*}$
}

Felipe Damasio

Instituto Federal de Educação, Ciência e Tecnologia de Santa Catarina

Rafael Ramos Maciel

Keterllin Farias Cidade

Josiane Trevisol Recco

Programa Institucional de Bolsas de Iniciação Científica - CNPq/IFSC

Adriano Antunes Rodrigues

Instituto Federal de Educação, Ciência e Tecnologia de Santa Catarina

Araranguá - SC

\section{Resumo}

O Instituto Federal de Educação, Ciência e Tecnologia de Santa Catarina oferece o curso de Licenciatura em Ciências da Natureza com habilitação em Física no campus Araranguá desde 2009. Este curso tem desenvolvido e promovido diversas ações de divulgação científica como meio de capacitar os professores em formação inicial para atuarem em ambientes não formais. Para articular estas ações foi fundado o Clube de Astronomia de Araranguá $\left(\mathrm{CA}^{2}\right)$ em 2012 por professores e alunos do curso de licenciatura do IFSC. A experiência de ensino aprendizagem relatada neste trabalho é uma das ações decorrentes do $\mathrm{CA}^{2}$ e foi intitulada "Luau Astronômico”, ela foi desenvolvida durante o ano de 2013. Além da formação inicial de professores, estes eventos também tiveram o objetivo

\footnotetext{
+ Astronomical Luau: the initial training of teachers as Science communicators in nonformal environments

* Recebido: janeiro de 2014.

Aceito: abril de 2014.
} 
de proporcionar um ambiente em que as duas condições que Ausubel preconiza para ocorrer a Aprendizagem Significativa ocorressem: predisposição em aprender e um material potencialmente significativo.

Palavras-chave: Espaços não formais. Divulgação científica. Astronomia. Formação de professores.

\begin{abstract}
The Instituto Federal de Educação, Ciência e Tecnologia de Santa Catarina offers the Bachelor Degree in Natural Sciences with specialization in Physics in Araranguá Campus since 2009. This course has promoted several actions in Science communication as a means of empowering teachers in initial training, also to work in non-formal environments. To articulate these actions it was founded the Astronomy Club of Ararangua $\left(C A^{2}\right)$ in 2012 by teachers and students of IFSC. The experience of teaching and learning described in this paper is one of the actions arising from $C A^{2}$ and it was entitled "Luau Astronômico", it was developed during the year 2013. Besides the initial training of teachers, this event also aimed to provide an environment in which the two conditions of Ausubel to have Meaningful Learning occur: predisposition to learn and a potentially significant material.
\end{abstract}

Keywords: Non-formal spaces. Science dissemination. Astronomy. Teacher training.

\title{
I. Introdução
}

No Projeto Pedagógico do Curso (PPC) de Licenciatura em Ciências da Natureza com habilitação em Física do campus Araranguá do Instituto Federal de Educação, Ciência e Tecnologia de Santa Catarina (IFSC) está definido como finalidade a formação de profissionais com ampla e sólida base teóricometodológica para a docência na área de Ciências da Natureza e de Física no Ensino Fundamental, no Ensino Médio e na Educação Profissional de nível médio. Visando atender às necessidades sócio-educacionais em consonância com os preceitos legais e profissionais em vigor, tal formação deve incluir espaços não for- 
mais no desenvolvimento de processos pedagógicos, principalmente relacionados com o conhecimento das ciências da natureza.

Para se alinhar ao projeto do curso, professores e alunos procuram desenvolver e implementar atividades que possam contribuir com a formação inicial dos licenciandos para atuarem como divulgadores científicos em ambientes não formais, além de produzir conteúdo de divulgação científica para a comunidade em geral (ALLAIN et al., 2011; DAMASIO; ALLAIN; EUZÉBIO, 2012; DAMASIO; ALLAIN; RODRIGUES, 2013; DAMASIO; MELO, 2013; RODRIGUES; DAMASIO; CUNHA, 2013). Para melhor articulação entre estas ações, as que abordam Astronomia, foi fundado em 2012 o Clube de Astronomia de Araranguá $\left(\mathrm{CA}^{2}\right)$, e as atividades de divulgação científica em ambientes não formais oriundas do estudo relatado neste artigo estão vinculadas ao $\mathrm{CA}^{2}$.

Quando se articula ações em ambientes não formais é preciso levar em consideração que não há consenso na literatura sobre a definição do termo (MARANDINO et al., 2003). No entanto, é possível apontar algumas características que podem diferenciá-la daquela exercida nos ambientes formais. Langhi e Nardi (2009) chamam de educação formal aquela que ocorre dentro do ambiente escolar, com planejamento para sistematizar o conhecimento, e caracterizam por educação não formal aquela com caráter coletivo, envolvendo práticas educativas fora do ambiente escolar, como por exemplo, museus, cursos livres, feiras e clubes de astronomia amadores.

A importância do currículo para diferenciar entre educação não formal e formal é ressaltada por Schivani (2010), sendo que a formal é aquela com currículo definido e a não formal negociado. Ainda destaca que a diferença não pode ser apenas o espaço físico (dentro ou fora de sala de aula), mas fatores como currículo, motivação e organização devem ser levados em conta. Por fim, faz-se uma ressalva quanto ao caráter não formal da educação prestada por clubes de astronomia amadores, caracterizando assim apenas atividades como observações astronômicas e exposições e como formal os cursos e oficinas que são oferecidos.

$\mathrm{O}$ projeto aqui relatado busca formas de articulação entre as atividades em ambientes não formais e atividades com currículo articulado e organizado e se estas tinham a potencialidade de contribuírem para a formação inicial de professores de forma a capacitá-los a atuar como divulgadores científicos em ambientes não formais de ensino. 


\section{Fundamentação Teórica}

A teoria de aprendizagem que norteou a elaboração do projeto foi a Teoria da Aprendizagem Significativa de David Ausubel que foi proposta originalmente em 1963; posteriormente, esta teoria teve contribuição de outros colaboradores, entre eles Marco Antonio Moreira com a Aprendizagem Significativa Crítica. A aprendizagem significativa acontece quando uma nova informação interage com conceitos relevantes pré-existentes na estrutura cognitiva do educando e é um processo no qual uma informação nova se relaciona, de forma não literal e não arbitrária, com uma já existente, ocorrendo uma interação entre essas informações. De outro lado, tem-se a aprendizagem mecânica, que acontece com frequência nas escolas, que se pode definir como sendo uma aprendizagem que não tem nenhuma interação com as concepções já existentes de conhecimento do aluno (MOREIRA; MASINI, 2001).

A teoria de Ausubel preconiza as condições para que aconteça a aprendizagem significativa. A primeira é em relação à natureza do material a ser aprendido pelo educando, sendo que a estrutura cognitiva do aluno deve relacionar os seus conceitos pré-existentes específicos com os deste novo material a ser aprendido, que seria o material potencialmente significativo. A segunda condição é que o aluno tenha predisposição em aprender e não apenas de memorizar, apesar de predisposição em aprender não significar prazer em aprender (MOREIRA, 2006).

Ausubel sugere princípios facilitadores para a formação de conceitos de maneira significativa: diferenciação progressiva, reconciliação integradora, organização sequencial e a consolidação. Por diferenciação progressiva, entende-se que se deve partir de uma ideia geral para os conceitos específicos de maneira progressiva; por reconciliação integradora, que se deve explorar as semelhanças e diferenças entre os conceitos e reconciliar suas inconsistências reais e aparentes; por organização sequencial, que se deve organizar de maneira sequencial-lógica os conteúdos e as relações entre si e, por consolidação, que se deve persistir no domínio, por parte do aluno, do conteúdo ensinado, antes de inserir outros conceitos, ou novos conhecimentos (MOREIRA; MASINI, 2001).

A principal sugestão da teoria para manipular a estrutura cognitiva do sujeito para facilitar a existência de condições necessárias à aprendizagem significativa é a estratégia chamada de organizador prévio. Esta estratégia pode ser constituída por materiais introdutórios apresentados antes do material instrucional em si, em um nível alto de generalização e abstração que serve de ponte entre o conhecimento prévio do sujeito e o campo conceitual que se pretende que ele aprenda 
significativamente. Organizadores prévios podem ser vistos como pontes cognitivas (MOREIRA, 2008).

Todas as ações do $\mathrm{CA}^{2}$ são planejadas de acordo com a Teoria da Aprendizagem Significativa de Ausubel. As atividades do clube, todas programadas e executadas pelos alunos licenciandos e professores, iniciam com um organizador prévio. Este organizador também é desenvolvido com a intenção de proporcionar nos estudantes a predisposição em aprender. A seguir, atividades potencialmente significativas são organizadas considerando os princípios da diferenciação progressiva, reconciliação integrativa, consolidação e organização sequencial. O que os alunos e professores procuram com estas atividades é criar um ambiente que conte com as duas condições preconizadas por Ausubel para que a Aprendizagem Significativa ocorra.

\section{O contexto do projeto}

O IFSC, Instituto Federal de Educação, Ciência e Tecnologia de Santa Catarina, é uma instituição pública federal com sede e foro em Florianópolis, capital do estado. O campus de Araranguá iniciou suas atividades em 2008, oferecendo cursos técnicos nas áreas de eletromecânica, têxtil (malharia e confecção) e moda. Em 2009, iniciou o curso de Licenciatura em Ciências da Natureza com habilitação em Física, que é voltado à formação de profissionais para o exercício da docência.

$\mathrm{O}$ curso de Licenciatura conta com escolas parceiras, às quais oferece cursos e atividades de extensão, dentre elas as que participaram das três edições do 'Luau Astronômico': E.E.B. Castro Alves, E.E.B. Maria Garcia Pessi, E.M. Nova Divineia e o próprio Ensino Médio Integrado do IFSC/Araranguá. São todas escolas públicas, sendo duas delas estaduais (uma de Ensino Médio e outra Fundamental), uma municipal (de Ensino Fundamental) e uma federal (de Ensino Médio).

O 'Luau Astronômico' pretendeu atingir, prioritariamente, os alunos do curso de Licenciatura, visando dar oportunidade para estes alunos trabalharem na organização e na realização de atividades de divulgação científica em ambientes não formais. Contudo, o projeto teve uma maior abrangência, já que atingiu também os alunos da Educação Básica, os quais eram carentes deste tipo de evento e abordagem da ciência. Por fim, o público mais amplo também era importante no preparo e na implementação das atividades, pois era incentivada a participação de familiares e amigos dos alunos das escolas parceiras. O público em geral era também convidado por meio de divulgação em rádios e televisão, bem como pelas redes sociais na internet. 


\section{Luau Astronômico}

A metodologia de cada edição foi discutida no início de 2013 entre professores e alunos do $\mathrm{CA}^{2}$. Nas reuniões de planejamento, no início do ano letivo, foi decidido que cada evento teria uma ideia-âncora que seria explorada de acordo com o princípio de Ausubel, da organização sequencial e, também, que seriam utilizados, como organizadores prévios, filmes, séries e documentários que abordassem a ideia-âncora de cada edição. Por fim, as atividades em sala de aula com currículo definido seriam realizadas iniciando com os conceitos mais gerais e diferenciando-os aos poucos (conforme o princípio da diferenciação progressiva) e as atividades de campo procurariam fazer a reconciliação integrativa.

Também foi decidido que haveria três edições do evento ao longo do ano letivo de 2013. Tal decisão foi tomada para que as ideias-âncoras pudessem utilizar os eventos astronômicos que por ventura estivessem na mídia. O envolvimento dos professores do curso de licenciatura foi diminuindo gradativamente a cada edição, permitindo maior autonomia aos estudantes (licenciandos), inclusive no gerenciamento dos recursos disponíveis. Desta forma foi possível avaliar o potencial da organização de tais atividades na capacitação dos licenciandos para atuarem em ações de divulgação científica em espaços não formais.

A estrutura de cada edição seria a de articular atividades de campo - como observação com telescópios e a olho nu, cursos de fotografia amadora e lançamento de foguetes - com atividades em sala de aula - como palestras, exibição de documentários e filmes. Todos os eventos se estenderiam pela madrugada, para justificar o nome do evento. Todas as atividades ocorreriam dentro do campus do IFSC-Araranguá, em seu pátio externo, auditório e na sede do $\mathrm{CA}^{2}$, e os alunos da licenciatura, além de organizadores, também seriam monitores de cada atividade.

O primeiro Luau Astronômico foi marcado para o dia oito de março, com início às $22 \mathrm{~h} 30$ e horário de término previsto para as $4 \mathrm{~h}$ do dia seguinte. A ideiaâncora adotada foi "cometas e asteroides", pois existia a possibilidade de observação do cometa Panstarss. As atividades planejadas e desenvolvidas durante o Luau foram: (i) observações com cinco telescópios que incluíram a Lua, o cometa Panstarss, planetas e demais objetos celestes, (ii) explicação de três painéis luminosos que abordavam escalas do Universo, vida e morte das estrelas e a escala temporal do Universo montados permanentemente na sede do $\mathrm{CA}^{2}$, (iii) palestras sobre temas diversos como cometas, planetas, estrelas e espectroscopia e (iv) sessão de cinema intitulada 'Cinema nas Estrelas', que exibiu o filme "Impacto Profundo", e posterior discussão. Para divulgação do evento, foi elaborado um cartaz para ser 
compartilhado nas redes sociais, que está reproduzido na Fig. 1, e uma matéria foi veiculada na televisão local ${ }^{1}$.

Após este primeiro evento, os professores e alunos do $\mathrm{CA}^{2}$ fizeram uma avaliação e tomaram algumas decisões para os próximos. A primeira foi limitar o número de participantes para 60 pessoas por atividade, encerrar o evento às $2 \mathrm{~h}$, diminuir o número de atividades, exibir na sessão de cinema obras mais curtas e solicitar um quilo de alimento não perecível aos visitantes. Todas estas decisões foram tomadas pelos estudantes de licenciatura e já foram válidas para a segunda edição do luau.

A data do segundo evento foi dia quinze de junho. A ideia-âncora foi "a formação dos elementos químicos". As atividades desenvolvidas foram às mesmas, porém o número de palestras foi diminuído e os temas alterados. A sessão de cinema ocorreu com exibição de episódios das séries "Os Simpsons" e "The Big Bang Theory”. Para divulgação do evento, foi também elaborado um cartaz que está reproduzido na Fig. 2, e entrevistas de divulgação foram feitas em rádios locais - como a para Band $\mathrm{FM}^{2}$.

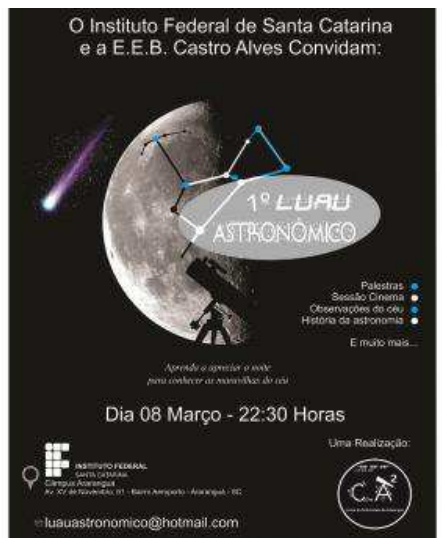

Fig. 1 - Cartaz de divulgação do $1^{o}$ Luau Astronômico.

$\mathrm{Na}$ avaliação do segundo evento foram tomadas algumas decisões pelos estudantes que seriam válidas para a próxima edição. A primeira foi incluir ativi-

\footnotetext{
${ }^{1}$ Disponível em: <http://youtu.be/p_DSxrvWmM4>.

2 Disponível em: <http://youtu.be/2usd14GggCA>.
} 
dades de astrofotografia que despertavam grande interesse no público nos dois primeiros eventos, não realizar atividades de recreação como a banda presente nos dois primeiros luaus, não fazer atividades paralelas, iniciar o evento às $20 \mathrm{~h}$ e concentrar todas as atividades de sala no auditório do campus Araranguá. Mais uma vez, toda esta avaliação foi feita pelos licenciandos.

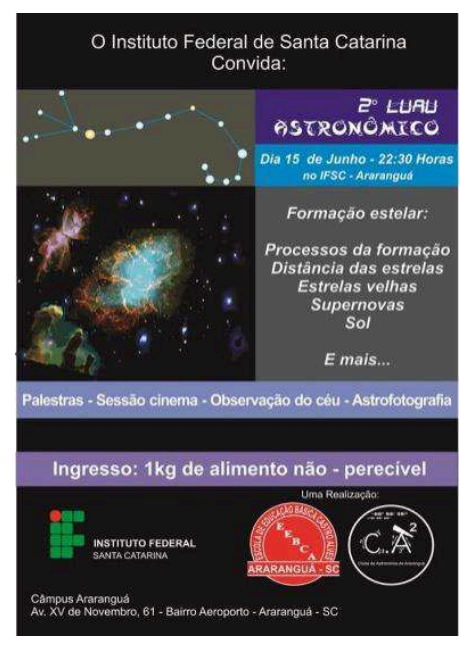

Fig. 2 - Cartaz de divulgação do $2^{\circ}$ Luau Astronômico.

O $3^{\circ}$ Luau foi marcado para vinte e nove de novembro e teve como ideiaâncora "estrelas e vida extraterrestre". As atividades desenvolvidas foram realizadas na seguinte ordem: (i) sessão de cinema que exibiu a série "ABC da Astronomia", (ii) palestras sobre vida extraterrestre e Diagrama H-R, (iii) observações com telescópios e a olho nu e (iv) curso de astrofotografia amadora e luminosidade estrelar. Para a divulgação do evento também foi elaborado um cartaz que está reproduzido na Fig. 3, e entrevistas de divulgação foram feitas em rádios locais como a para Rádio Araranguá $\mathrm{AM}^{3}$.

A cada evento, os professores se envolveram menos, procurando dar autonomia aos licenciandos. No primeiro, participaram ativamente da organização, divulgação e realização das ações. E, após a sua realização, participaram da avaliação de maneira bastante presente.

${ }^{3}$ Disponível em: <http://youtu.be/mOBDGBj5VPg>. 


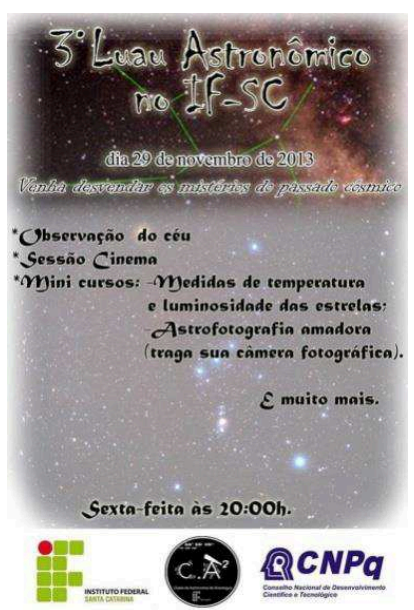

Fig. 3 - Cartaz de divulgação do $3^{\circ}$ Luau Astronômico.

Já no planejamento do segundo, procuraram cada vez se afastar mais da organização e definição de temas e mesmo da administração dos recursos que estavam disponíveis. No terceiro evento, os professores do $\mathrm{CA}^{2}$ participaram apenas em questões burocráticas, como assinaturas de autorizações, mas as questões técnicas foram todas definidas pelos estudantes da Licenciatura, bem como sua divulgação. Eles escolheram inclusive os palestrantes, os temas e tempo que eles teriam.

Esta capacidade de organizar quase de maneira independente o $3^{\circ}$ Luau indica que a estratégia utilizada para permitir aos licenciandos a competência durante sua formação inicial para atuarem como divulgadores científicos em ambientes não formais teve indicativos positivos. Ainda mais, o formato inicial do evento, pensado pelos professores, foi muito reformulado pelos estudantes, de acordo com suas avaliações, o que é um sinal que, no transcorrer do ano, os licenciandos sentiram-se tão mais seguros em trabalhar em ambientes não formais que puderam reorganizar uma abordagem pensada por seus professores.

O evento melhor avaliado pelos licenciandos, professores da Licenciatura e pelo público foi justamente o terceiro - aquele que mais contou com a participação dos licenciandos. Este é mais um indicativo que eles desenvolveram a competência de planejar, desenvolver e avaliar ações em ambientes não formais de divulgação científica. 


\section{Considerações finais}

Os PCN+ colocam a necessidade de o professor promover e interagir com meios culturais e de difusão científica, entre eles, os de ambientes não formais, como centros tecnológicos, observatórios, museus e centros de ciências (BRASIL, 2002). Porém, o ensino de Ciências tem se dedicado quase exclusivamente aos espaços formais. Em relação à Astronomia na escola, raramente é ensinada e menos ainda com atividades interativas e práticas, como as observações, e, quando é abordada, fica restrita às informações contidas nos livros didáticos. A interação entre espaços não formais e formais pode possibilitar ao aluno ser agente de seu próprio conhecimento (AROUCA et al., 2012). É neste sentido que a realização dos luaus tem sua importância, como possibilidade de articulação entre espaços formais e não formais.

O grande empecilho que dificulta que as questões colocadas anteriormente cheguem à sala de aula é que os professores não são formados para atuarem em espaços não formais e como divulgadores científicos, sendo esta uma lacuna a ser preenchida nos cursos de formação inicial de professores. Esta necessidade é reconhecida pelo PPC da Licenciatura em Ciências da Natureza com habilitação em Física do IFSC/Araranguá, quando exige que o curso possibilite o desenvolvimento da competência nos licenciandos para trabalharem em ambientes não formais de ensino. $\mathrm{O}$ projeto relatado procurou desenvolver atividades que contemplem a formação docente exigida pelo PPC e pelo PCN+.

\section{Referências}

ALLAIN, O. et al. Choque de Ciência: ensino, pesquisa e extensão indissociados no ensino de inglês e ciências. In: CONGRESSO BRASILEIRO DE EXTENSÃO UNIVERSITÁRIA, 5., 2012, Porto Alegre. Anais... Porto Alegre: EDIPUCRS, 2011. v. 1. p. 74-78.

AROUCA, S. C.; COLOMBO Jr, P. D.; SILVA, C. C. Tópicos de Física Solar no Ensino Médio: Análise de um curso com atividades práticas no Observatório Dietrich Schiel. Revista Latino-Americana de Educação em Astronomia, n. 14, p. 7-25, 2012.

BRASIL. PCNs+, Ensino Médio: orientações educacionais complementares aos Parâmetros Curriculares Nacionais. Ciências da Natureza, Matemática e suas Tecnologias. Brasília: Ministério da Educação, SEMTEC, 2002. 
DAMASIO, F.; ALLAIN, O.; EUZÉBIO, G. J. O uso da exposição "Ciência Massa" como atividade não formal para a formação de professores licenciandos em Ciências da Natureza. Ciências \& Cognição, v. 17, n. 2, p. 185-205, 2012.

DAMASIO, F.; ALlAIN, O.; RODRIGUES, A. A. Clube de Astronomia de Araranguá: a formação de professores de ciência como divulgadores científicos. Revista Latino-Americana de Educação em Astronomia - RELEA, n. 15, p. 65-77, 2013.

DAMASIO, F.; MELO, M. D. A fundamentação teórica na Teoria da Aprendizagem Significativa do projeto vencedor do concurso 'Minha ideia dá um sala 2012' da TV Escola. Experiências em Ensino de Ciências, v. 8, n. 2, p. 70-79, 2013.

LANGHI, R.; NARDI, R. Ensino de astronomia no Brasil: educação formal, informal, não formal e divulgação científica. Revista Brasileira de Ensino de Física, v. 31, n. 4, 4402, 2009.

MARANDINO, M. et al. A educação não formal e a divulgação científica: O que pensa quem faz? In: ENCONTRO NACIONAL DE PESQUISA EM ENSINO DE CIÊNCIAS, 4., 2003, Bauru. Livro de Resumos... Bauru: ABRAPEC, 2003.

MOREIRA, M. A. Organizadores prévios e a aprendizagem significativa. Revista Chilena de Educación Científica, v. 7, n. 2, p. 23-30, 2008.

MOREIRA, M. A. A teoria da aprendizagem significativa e sua implementação em sala de aula. Brasília: Editora da UnB, 2006.

MOREIRA, M. A.; Masini, E. F. S. Aprendizagem Significativa: a teoria de David Ausubel. São Paulo: Centauro Editora, 2001.

RODRIGUES, A. A.; DAMASIO, F; CUNHA, S. L. S. Divulgação científica na formação docente: construindo e divulgando conhecimento por meio do rádio e da internet. Experiências em Ensino de Ciências, v. 8, n. 2, p. 80-94, 2013.

SCHIVANI, M. Educação não formal no processo de ensino e difusão da Astronomia: ações e papéis dos clubes e associações de astrônomos amadores. 2010. 174p. Dissertação (Mestrado em Ensino de Física) - Instituto de Física da Universidade de São Paulo, 2010. 